\title{
Como e com quem você quer falar? Um estudo sobre os públicos envolvidos no processo da comunicação de marketing de grandes anunciantes
}

\author{
How and with whom you want to talk? A study of the public involved \\ in the process of communication marketing big advertisers
}

\section{Resumo}

O objetivo do estudo é compreender como as empresas abordam a questão das múltiplas audiências no planejamento de suas campanhas promocionais. De forma específica, pretende identificar quais públicos considerados no processo da comunicação, revelar quais são prioritários nas estratégias e aqueles que exercem maior influência na condução das atividades. Os dados da pesquisa empírica foram coletados por meio de entrevista em profundidade em dez grandes anunciantes. Os resultados apontam que as empresas buscam contemplar outros públicos, em especial, o público interno, imprensa e influenciadores. Em praticamente todos os casos os gestores da comunicação de marketing precisam acionar áreas de contato com esses públicos para colocar em prática suas estratégias.
\end{abstract}

Fabiano Palhares Galão

Edson Crescitelli ${ }^{2}$

Palavras-chave: Comunicação de marketing; Público-alvo; Planejamento da comunicação.

\begin{abstract}
The aim of this study is to understand how companies have addressed the question of multiple audiences in planning their promotional campaigns. In particular, the study intend to identify which public considered in the process of marketing communications, reveal which are priority in the strategies and those who have more influence in the marketing activities. Data were collected through in-depth interview in ten advertisers. The results show that companies seek to include other stakeholders in the process of marketing communication, in particular, the internal public, press and influencers. In virtually all cases, managers of marketing communications need to trigger areas in contact with these groups to put into practice their strategies.
\end{abstract}

Keyword: Marketing communications; Target; Communication planning.

\begin{abstract}
1fabiano.galao@hotmail.com, Brasil. Professor Adjunto da Universidade Tecnológica Federal do Paraná - UTFPR. Doutorando em Administração na Universidade de São Paulo - USP. Rua Marcílio Dias, 635, Jardim Paraíso, CEP: 86812460 - Apucarana, PR - Brasil.

2edsonc@usp.br, Brasil. Professor Doutor da Universidade de São Paulo - USP. Doutor em Administração pela Universidade de São Paulo - USP. Av. Luciano Gualberto, 908, Cidade Universitária, CEP: 05508-900 - São Paulo, SP Brasil.
\end{abstract}

Recebido em 20.09.2012

Aprovado em 02.06.2014

Revista Administração em Diálogo

ISSN 2178-0080

Programa de Estudos Pós-Graduados em Administração

Pontifícia Universidade Católica de São Paulo 


\section{Introdução}

A comunicação de marketing se desenvolve por meio de um processo de análise, planejamento e implementação de um conjunto de conceitos, elementos de decisão e técnicas específicas, e tem por objetivo principal estimular e preservar o diálogo, o relacionamento e as trocas comerciais por meio da informação e persuasão entre a organização e os públicos com os quais ela se relaciona. No processo de desenvolvimento da comunicação de marketing, são várias as decisões que são tomadas, como por exemplo, a escolha das formas e meios de comunicação, a definição da verba que será utilizada para a realização dos esforços, a determinação dos critérios de avaliação dos resultados e a seleção do público-alvo das mensagens.

Shimp (2009, p.39) afirma que a seleção do público dá início ao processo de comunicação, e o autor inclui esta determinação no chamado grupo de decisões fundamentais, evidenciando a importância da atividade para o desempenho do processo e uma etapa crítica para a elaboração de uma comunicação de marketing eficiente e eficaz. Kotler e Keller (2006, p. 538) confirmam a relevância da definição do público-alvo sublinhando que tal decisão exerce uma influência fundamental em todas as atividades de comunicação.

Muito embora grande parte do investimento de comunicação de marketing seja destinado, dentre outras coisas, para atrair a atenção e preservar a boa imagem das organizações junto ao mercado consumidor, outros grupos de interesse também devem ser contemplados no processo de comunicação. Dessa forma, pode-se citar, por exemplo, o público interno, especialmente aqueles que têm contato direto com o consumidor, que deve ser informado sobre as campanhas e projetos de comunicação em andamento, os intermediários que precisam ter informações corretas e claras a respeito dos benefícios e diferenciais dos produtos dos fabricantes, e a imprensa que também deve ser contemplada no sentido de disseminar as notícias e fatos relevantes da empresa e de seus produtos nos veículos de comunicação e auxiliar no processo de construção da imagem de marca pretendida por ela. Além disso, a necessidade de envolver diversas audiências pode garantir maior impacto e cobertura do conteúdo das mensagens enviadas, atendendo assim aos requisitos da comunicação integrada de marketing (CIM). 
Fill (2002, p.I2) reforça essa ideia e destaca que a comunicação de marketing não deve ser destinada apenas ao consumidor final, mas sim, para as várias audiências com as quais uma organização se relaciona. Smith, Berry e Pulford (1997, p.8) são mais específicos quando discutem a composição do público-alvo da comunicação e argumentam que o escopo da comunicação de marketing é amplo e envolve o envio de mensagens para o público interno (funcionários, equipe de vendas, serviço de atendimento ao cliente) e também externo, envolvendo nesse caso os clientes atuais e potencias e outros grupos de interesse.

Diante do exposto, este artigo busca compreender como as empresas têm abordado a questão das múltiplas audiências no planejamento de suas campanhas promocionais. De forma específica, o estudo pretende identificar quais públicos são considerados pelas empresas no processo da comunicação de marketing, revelar quais os grupos prioritários nas estratégias de comunicação e aqueles que exercem maior influência na condução das atividades de marketing, além de evidenciar as estratégias de contato implementadas pelas empresas para atingir os públicos selecionados.

O trabalho é de caráter exploratório e de abordagem qualitativa. Para a coleta de dados, optou-se pela entrevista em profundidade utilizando um roteiro de questões. As entrevistas foram aplicadas em dez empresas, onde, em cada uma delas, um gestor da área de comunicação foi entrevistado. As empresas foram selecionadas a partir do ranking dos maiores anunciantes do Brasil referente ao ano de 2OII, publicado pelo jornal Meio \& Mensagem. A análise de dados foi conduzida segundo os postulados da análise de conteúdo.

O artigo está organizado em quatro partes, além desta introdução. A primeira parte contempla a revisão bibliográfica sobre o tema central. Em seguida o método do estudo é detalhado e posteriormente os resultados são analisados. Por fim, as conclusões da pesquisa e suas limitações são apresentadas, em conjunto com as sugestões de estudos futuros.

\section{Revisão bibliográfica}

A revisão bibliográfica do estudo aborda, em um primeiro momento, o papel da comunicação de marketing e discute em seguida os diferentes tipos de públicos que 
podem ser envolvidos nas estratégias de comunicação de marketing das organizações.

A comunicação é uma atividade que se desenvolve nas mais diversas situações e realidades sociais. No contexto de uma organização, a comunicação cumpre uma função importante, pois permite, fundamentalmente, que ela se mantenha em constante interação com os diversos agentes que participam do seu ambiente de atuação.

Shimp (2009, p.26) destaca o papel da comunicação de marketing, afirmando que ela é considerada um aspecto crítico das missões de marketing gerais das empresas e um importante fator determinante do sucesso ou fracasso dessas empresas. Para Shimp (20o9, p.26) todas as organizações, sejam aquelas atuantes no mercado de consumo ou empresarial, e até mesmo as sem fins lucrativos, usam várias formas de comunicação de marketing para promover suas ofertas e alcançar metas financeiras e outros objetivos. Sob outro ponto de vista, Schultz, Tannenbaum e Lauterborn (I994, p.49) esclarecem que a comunicação de marketing tem um papel relevante para as empresas, principalmente em setores onde a competição é grande e a busca pela atenção do consumidor tem se tornado um processo cada vez mais crítico, em virtude da proliferação de mensagens publicitárias.

O público-alvo da comunicação de marketing, quando analisado sob o ponto de vista do processo básico de comunicação, corresponde ao conjunto dos receptores que interessam à organização (emissor). Porém, Ogden e Crescitelli (2007, p. I7) argumentam que entender o público-alvo da comunicação de marketing como sendo apenas o consumidor final significa adotar uma visão distorcida do processo. Fica claro com isso que, ao se pensar nessa modalidade de comunicação, a organização deve ampliar o alcance de seus efeitos para além dos seus clientes atuais, podendo incluir os clientes potenciais, influenciadores e agentes do canal de distribuição (THORSON; MOORE, I996, p.4). Fill (2OO2, p.23) coloca que o ponto central da comunicação de marketing é justamente reconhecer a necessidade de se comunicar com diversos públicos (muitas vezes de forma simultânea), e compreender que cada um deles possui requisitos de informação distintos, uma vez que todas as organizações desenvolvem uma série de relacionamentos com uma ampla variedade de outras organizações, grupos de interesse e, naturalmente, com os consumidores de seus produtos.

Para Fill (2002, p.23) o objetivo com isso é gerar e transmitir mensagens que 
apresentem a organização e suas ofertas para seus vários públicos, incentivando-os a estabelecer com ela o diálogo e um relacionamento de longo prazo. Kliatchko (20o8, p.I45) também é a favor da ampliação da cobertura dos esforços de comunicação e indica a relevância dessa prática de modo similar ao de Fill. Para Kliatchko (20o8, p.I45), gerenciar a comunicação de marketing com os diversos públicos de relacionamento significa que todo o seu processo de desenvolvimento coloca o mercado alvo no centro do processo de negócio, de modo a efetivamente atender as suas necessidades e desejos e estabelecer relacionamentos de longo prazo e lucrativo com eles.

Tendo como princípio que a comunicação deve ser dirigida a múltiplas audiências, Ogden e Crescitelli (2007, p. I7) classificam o público-alvo da comunicação em quatro tipos, os quais serão apresentados na sequência: público interno, intermediário, consumidor e comunidade.

No que se refere ao público interno, Ogden e Crescitelli (2007, p. I7) colocam que todos os funcionários da organização devem ser considerados no programa de comunicação de marketing e reconhecem que, mesmo sendo um público restrito, ele possui alta credibilidade por representar a empresa perante o mercado. Os mesmos autores fazem dois alertas relacionados à gestão da comunicação de marketing com o público interno. No primeiro alerta, Ogden e Crescitelli (2007, p. I7) lembram que os funcionários da organização que possuem contato direto com o cliente (assistência técnica, call centers, televendas e cobrança), devem receber uma atenção maior por parte dos gestores de comunicação em virtude da sua influência e papel estratégico. A segunda observação diz respeito ao conteúdo das mensagens que são destinadas ao público interno. Nesse caso, Ogden e Crescitelli (2007, p. I7) destacam que "[...] o foco dessa abordagem é a mensagem comercial - a mesma que é transmitida ao mercado -, e não as comunicações internas da empresa [...]”, as quais são desenvolvidas normalmente pelo departamento de recursos humanos. Crescitelli e Ikeda (2006, p.5) complementam que, como os funcionários são uma fonte de contato com clientes, eles precisam estar muito bem informados sobre as ações de marketing desenvolvidas pela organização. Crescitelli e Ikeda (2006, p.5) incluem no público interno os funcionários terceirizados da organização e os prestadores de serviços, por considerarem que estes agentes são uma fonte de contato com clientes com alto grau de interatividade. Abordagem similar é 
apresentada por Fill (2002 p.I74), o qual, além de também citar esses dois tipos de públicos, inclui ainda os funcionários temporários como possíveis alvos dos esforços de comunicação.

O segundo tipo de público-alvo considerado por Ogden e Crescitelli (2OO7, p. I7) são os intermediários, ou seja, aqueles que compõem a cadeia de distribuição dos produtos ofertados por uma organização. Moore e Thorson (I996, p.I43) também adotam essa abordagem e dizem que o profissional responsável pela comunicação de marketing deve identificar as audiências que desempenham um papel na venda dos produtos, seja de forma direta ou não. Nesse caso, os autores incluem os membros do canal de distribuição como um público potencial para os esforços de comunicação da organização.

Normalmente no grupo dos intermediários estão os distribuidores, revendedores, atacadistas e varejistas e, de modo mais específico, Ogden e Crescitelli (2007, p. I7) entendem que dentro da estrutura de cada um deles é necessário identificar os indivíduos com poder de decisão de compra, como o corpo diretivo da empresa, seus compradores e vendedores. A realização de esforços de comunicação com os intermediários é considerada por Anderson e Vincze (2004, p.380) um aspecto essencial no contexto das estratégias de comunicação de marketing, sendo que inclusive, este grupo recebe investimentos significativos por parte das organizações interessadas em estabelecer um relacionamento comercial mais produtivo com os agentes participantes do canal de distribuição. Ikeda e Crescitelli (2002, p.9) são enfáticos em defender o uso da comunicação com esse tipo de público e afirmam que, independentemente da estrutura de distribuição, os intermediários devem ser envolvidos no processo de comunicação de marketing, recebendo informações de mesmo conteúdo, seja qual for recurso de comunicação utilizado, dada a importância do papel desempenhado por eles no processo de comercialização.

O público consumidor (clientes atuais e potenciais) corresponde ao terceiro grupo na perspectiva de Ogden e Crescitelli (2007, p. I7), os quais o consideram como aquele que, na maioria dos casos, merece mais atenção por parte das empresas. A definição do público consumidor, envolvendo em sentido mais restrito as informações fundamentais a cerca do seu perfil, estilo de vida, comportamento, dentre outras 
questões, é resultado dos processos de segmentação e seleção de mercado alvo, os quais são considerados essenciais para a criação das diretrizes de comunicação e para o sucesso das atividades de marketing e da própria organização. Ikeda e Crescitelli (2002, p.9) ressaltam que uma ação de comunicação deve considerar dois tipos distintos de clientes finais: as pessoas físicas e jurídicas, em virtude das “[...] diferenças fundamentais em seus padrões de sensibilização em relação às mensagens emitidas”.

O público-alvo denominado de “comunidade” por Ogden e Crescitelli (2007, p. I8) é amplo e compreende setores como a imprensa, governo, organizações não governamentais, sindicatos, associações, dentre outros. Na avaliação deste grupo os autores também fazem algumas observações pertinentes e lembram que, embora este público geralmente seja foco da comunicação corporativa, alguma atenção deve ser destinada a ele, dado que alguns componentes desse grupo, como a imprensa, exercem grande influência na opinião pública.

Rossiter e Percy (I997, p.57) apresentam uma abordagem que envolve cinco grupos de públicos que uma organização poderia determinar com alvo de sua comunicação. A base para a caracterização dos grupos adotada pelos autores é a lealdade à marca e, segundo eles, é a abordagem mais apropriada para realizar uma comunicação bem sucedida. O primeiro grupo definido por Rossiter e Percy $(1997$, p.58) é formado por indivíduos que não são clientes de uma determinada organização. Nesse caso, três subgrupos de consumidores são encontrados. O primeiro corresponde aos possíveis novos usuários da categoria, ou seja, são indivíduos que ainda não são usuários de determinado produto, seja da empresa em análise ou da concorrência, mas que podem representar um bom potencial de compras dependendo do conhecimento deles a respeito da categoria de produtos. Assim, dentro desse subgrupo os autores identificam três categorias: aqueles que possuem uma atitude positiva com a categoria de produtos (bons clientes potenciais), os que simplesmente desconhecem a categoria dos produtos e aqueles que apresentam uma disposição negativa em relação à categoria. Para os que desconhecem a categoria dos produtos Rossiter e Percy (I997, p.526) indicam que a estratégia de comunicação deve ser feita no sentido de educar os indivíduos para tornálos conscientes a respeito da categoria, com a esperança de que sua atitude se torne positiva e assim seja atraído pela empresa. 
A proposta de Rossiter e Percy (1997, p.58) inclui ainda um subgrupo de indivíduos que opta por outras marcas, não sendo fiel a nenhuma delas e que por algum motivo não inclui a marca de determinada organização em seu conjunto de escolha. Isso pode ocorrer caso o grupo não conheça a marca ou tem uma atitude negativa em relação a ela. Rossiter e Percy (I997, p.58) sugerem neste caso um possível reposicionamento da marca e alguma alteração no mix de comunicação de forma a atingir com mais efetividade esse grupo. Por fim, o quinto subgrupo de usuários são aqueles que apresentam o menor potencial de vendas para determinada organização, pois exibem uma forte fidelidade a pelo menos uma outra marca concorrente. O desafio da comunicação neste caso é romper a lealdade, porém, Rossiter e Percy $(1997$, p.58) argumentam que essa tarefa é bastante complexa.

O segundo grande grupo corresponde àqueles que são clientes da organização. Nesse grupo estão os usuários leais às marcas, que possuem o máximo conhecimento e uma atitude favorável em relação a elas. Para Rossiter e Percy (I997, p.58) essa parcela representa a principal fonte das atuais e futuras vendas, pois são os compradores mais frequentes. Segundo os autores, a comunicação neste caso deve ser concentrada na construção do relacionamento e na recompensa pela lealdade. Também fazem parte deste grupo os indivíduos que possuem uma fraca preferência pelas marcas de determinada organização, sendo compradores menos frequentes e por isso, têm predisposição para optar, seja de forma experimental ou rotineira, por marcas concorrentes. Para este subgrupo, chamado por Rossiter e Percy $($ I997, p.526) de favoráveis a trocas de marca, os autores sugerem que a comunicação busque manter e reforçar a consciência e preferência da marca.

A figura I representa a proposta de Rossiter e Percy (I997, p.526), expondo os cinco grupos de públicos que foram descritos de acordo com a categorização feita. 
Figura I - Tipos de públicos envolvidos na comunicação de marketing

\begin{tabular}{|c|c|}
\hline Grupos que não são clientes & $\begin{array}{l}\text {-Novos usuários da } \\
\text { categoria } \\
\text {-Usuários que trocam de } \\
\text { marcas concorrentes } \\
\text {-Leais a outras marcas }\end{array}$ \\
\hline Grupos que são clientes & $\begin{array}{l}\text {-Leais à marca } \\
\text { •Favoráveis a trocar de marca }\end{array}$ \\
\hline
\end{tabular}

Fonte: Adaptado de Rossiter e Percy (I997, p.57)

As mensagens da comunicação de marketing de uma organização também podem ser direcionadas para os chamados líderes de opinião e/ou para os formadores de opinião (CRESCITELLI; IKEDA, 20o6, p.3), os quais constituem um tipo de público que, embora não tenha contato direto com a organização e muitas vezes não são usuários dos seus produtos, tem condições de influenciar a decisão de compra do consumidor final. O poder de influência desse grupo faz com que as organizações desenvolvam programas de marketing especialmente concebidos para ele (NICKELS; WOOD, I999, p.IIo) e, em se tratando do planejamento e execução do plano de comunicação de marketing, Fill (2002, p. 4I) alerta que a importância dos lideres de opinião não deve ser subestimada.

Os líderes de opinião, segundo Nickles e Wood (ı999, p.IIo), são pessoas que aconselham ou orientam os consumidores quando esses precisam de alguma informação de determinados produtos, suas características, vantagens e desvantagens. Dahlen, Lange e Smith (20IO, p. 396) citam que os líderes são indivíduos que têm influência sobre os consumidores pertencentes ao seu próprio grupo social e por isso possuem um papel de destaque na disseminação de informação e criação de imagem da organização e seus produtos. Já os formadores de opinião, de acordo com Fill (2002, p.42), são pessoas que são capazes de exercer influência pessoal por causa da sua autoridade, formação ou status associados com o objeto do processo de comunicação. Para o autor, os formadores de opinião são procurados por outras pessoas para fornecer informações e conselhos, assim como os líderes de opinião, porém, essa busca é feita em virtude da experiência formal detida pelo grupo. Como exemplo, o autor cita os médicos 
especialistas, farmacêuticos, editores de revistas e de programas de TV. Dahlen, Lange e Smith (20IO, p. 396) acrescentam que, além da experiência formal, os formadores de opinião são alvo dos consumidores para a busca de informações e das organizações para a disseminação delas por conta da credibilidade e imparcialidade atribuída ao grupo. Diante de suas características, os líderes e formadores de opinião serão denominados de influenciadores.

Para finalizar esta seção, a figura 2 proporciona uma visão integrada de todos os públicos potencias que podem ser envolvidos nas estratégias de comunicação de marketing de acordo com a revisão da literatura.

Figura 2 - Tipos de públicos que podem ser envolvidos na comunicação de marketing

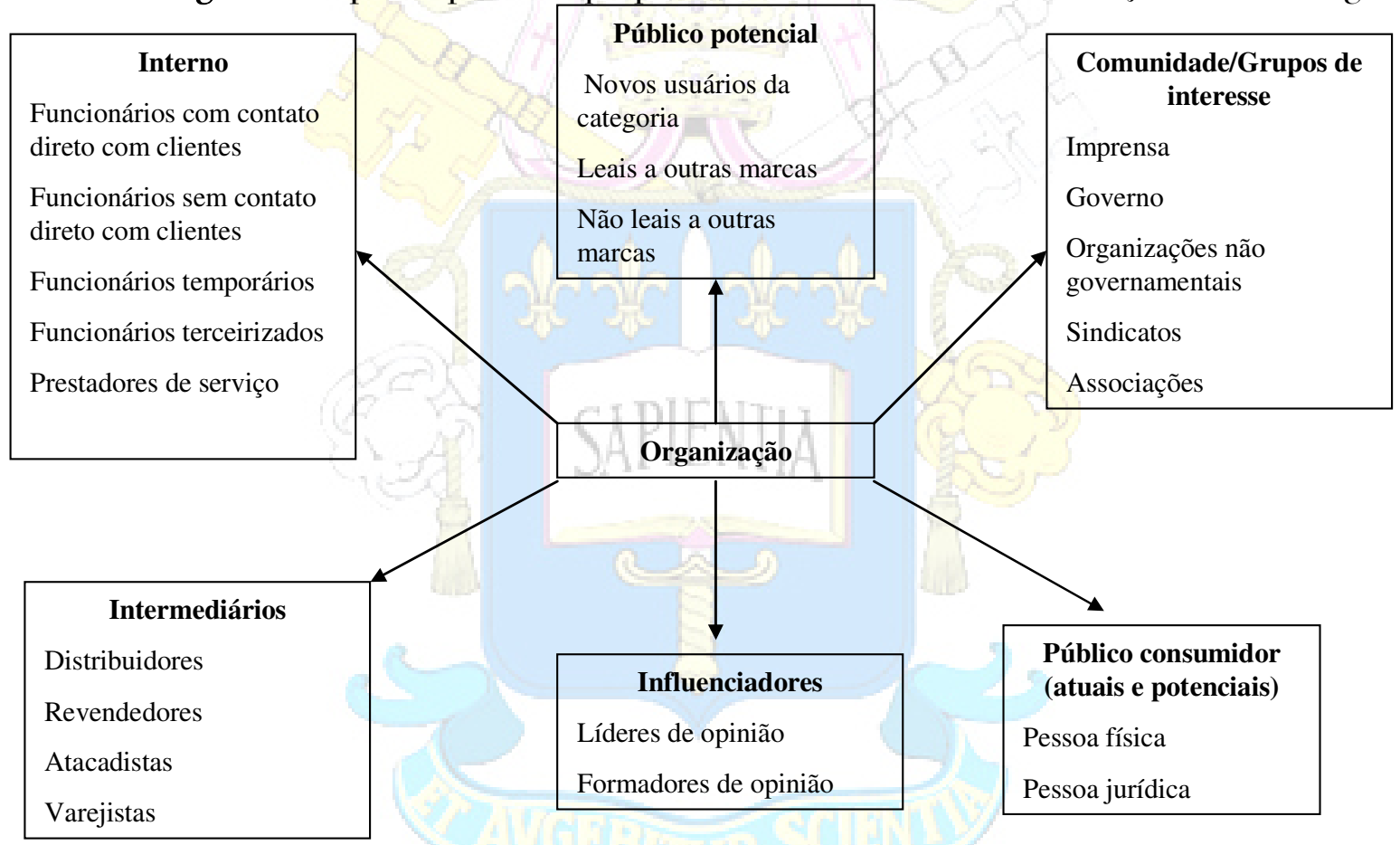

Fonte: Elaborado pelos autores

\section{Materiais e métodos}

A presente seção delineia os aspectos metodológicos da pesquisa empírica e descreve o método de coleta dos dados, os critérios adotados para a seleção da amostra e os procedimentos de análise.

A pesquisa é de caráter exploratório e de abordagem qualitativa. Para a coleta de dados, optou-se pela entrevista em profundidade baseada em um roteiro de questões, 
considerada por Daymon e Holloway (2OII, p. 220) como a principal fonte de dados em pesquisas qualitativas. Duarte (2005, p.62) destaca a flexibilidade na aplicação do método e diz que a entrevista em profundidade permite ao informante definir os termos da resposta e ao entrevistador ajustar livremente as perguntas que são feitas. Para o autor, esse tipo de entre $\neg$ vista procura intensidade nas respostas, e não a quantificação ou representação es`tatística das informações, aspectos condizentes com os propósitos deste trabalho.

As entrevistas foram aplicadas em io empresas, onde, em cada uma delas, um gestor da área de comunicação foi entrevistado. As empresas foram selecionadas a partir do ranking dos 300 maiores anunciantes do Brasil referente ao ano de 20 II publicado pelo jornal Meio \& Mensagem. Para tornar o processo de seleção mais objetivo diante da grande quantidade de empresas, determinou-se em um primeiro momento que as empresas que fariam parte do estudo deveriam figurar na lista dos dez maiores anunciantes de cada um dos cinco principais setores econômicos que compõem o ranking, a saber: i) comércio varejo, ii) serviços ao consumidor, iii) veículos, peças e acessórios, iv) mercado financeiro e seguros, e v) higiene pessoal e limpeza. Além de contribuir para a objetividade do processo de seleção, a existência de empresas de diferentes setores também torna mais rica a discussão dos resultados.

Os contatos foram feitos pela ordem de classificação das empresas em cada um dos cinco setores e diante das condições para a realização da pesquisa e da já esperada dificuldade de acesso às empresas, adotou-se durante o processo de seleção uma postura mais flexível com o objetivo de: i) abarcar outros setores, além dos cinco principais, e ii) incluir empresas que ocupassem outras posições a partir da IO a colocação. Como resultado final desse processo, 35 empresas foram contatadas por e-mail e telefone, das quais, I5 não aceitaram em participar por motivos diversos (falta de interesse, indisponibilidade de horário do entrevistado, restrições internas) e ıo não retornaram as ligações e/ou e-mail. Com isso, chegou-se a um total de Io empresas pesquisadas de 7 setores econômicos, sendo que os dois setores incluídos foram o de informática e eletroeletrônicos.

Quatro entrevistados solicitaram que o nome da empresa não fosse revelado no estudo e para padronizar a apresentação dos resultados, ficou estabelecido que nenhum 
nome seria informado. Todas as entrevistas foram gravadas e feitas pessoalmente. Tomou-se o cuidado de que o agendamento da pesquisa fosse feito com pessoas que ocupassem cargos relacionados diretamente com a área de comunicação de marketing, ou que pelo menos tivessem um envolvimento com as principais decisões da área.

O quadro I lista o setor econômico das empresas pesquisadas de acordo com a nomenclatura utilizada no ranking e também o cargo dos entrevistados.

Quadro I - Setor econômico das empresas pesquisadas e cargo dos entrevistados

\begin{tabular}{|c|c|c|}
\hline & Setor econômico & Cargo do entrevistado \\
\hline Fmpresin 1 & Veículos, pegas e acesó́rios & Diretor de marketing \\
\hline Empresa 2 & Servicos ao consumidor & Gerente de finteligencia de Mercado \\
\hline Empresa 3 & Eletro-Eletronicos & Geremle de manketing \\
\hline Empresa 1 & Mercado financeiro e seguros & Coondenadora de marketing digital \\
\hline Empnesa 5 & Combrcio varejo & Gerente de propaganda \\
\hline Empresa 6 & Informútica & Gerente de commicação \\
\hline Emprosa 7 & Elktro-Eletronicos & Germite de Fincligencia de Mercado \\
\hline Fimpresa 8 & Mercado financeiro e seguros & Vice-presidente executivo de marketing \\
\hline Empresa 9 & Comércio varejo & Gerente de marketing \\
\hline Eimpresn 10 & Higienepessoal e belers & Coondenador de Brand building \\
\hline
\end{tabular}

Fonte: Elaborado pelos autores

Para sistematizar e interpretar os resultados das entrevistas de maneira clara e objetiva o método de análise adotado neste estudo foi a análise de conteúdo, instrumento de análise interpretativa cada vez mais utilizado nos estudos organizacionais (DELLAGNELO; SILVA, 2005, p.97; MOZZATO, 20IO, p.I), que busca, por meio de um conjunto de técnicas, sistematizar o conteúdo das mensagens e o significado desse conteúdo, tendo como referência o emissor da mensagem, o contexto ou os seus efeitos (OLIVEIRA et al., 2003, p.3). Os dados foram analisados de acordo com os procedimentos estabelecidos por Bardin (2OII), a qual determina que o processo seja feito em três etapas: i) pré-análise, ii) exploração do material, iii) tratamento dos resultados, inferência e interpretação.

A pré-análise tem por objetivo organizar o material coletado e sistematizar as idéias iniciais, de modo a compor um esquema preciso de desenvolvimento de todo o processo de análise. Nesta etapa foram feitas as transcrições das entrevistas, a leitura Revista Administração em Diálogo ISSN 2178-0080 
cuidadosa dos textos e a eliminação de trechos que não tratavam do assunto principal.

Em seguida foram identificadas as proposições que representam a única categoria de análise, que neste estudo compreende o tema público-alvo. As proposições que emergiram nas entrevistas estão no quadro 2.

Quadro 2 - Público-alvo da comunicação de marketing

\begin{tabular}{|c|c|}
\hline Proposicoes & Referenclas \\
\hline 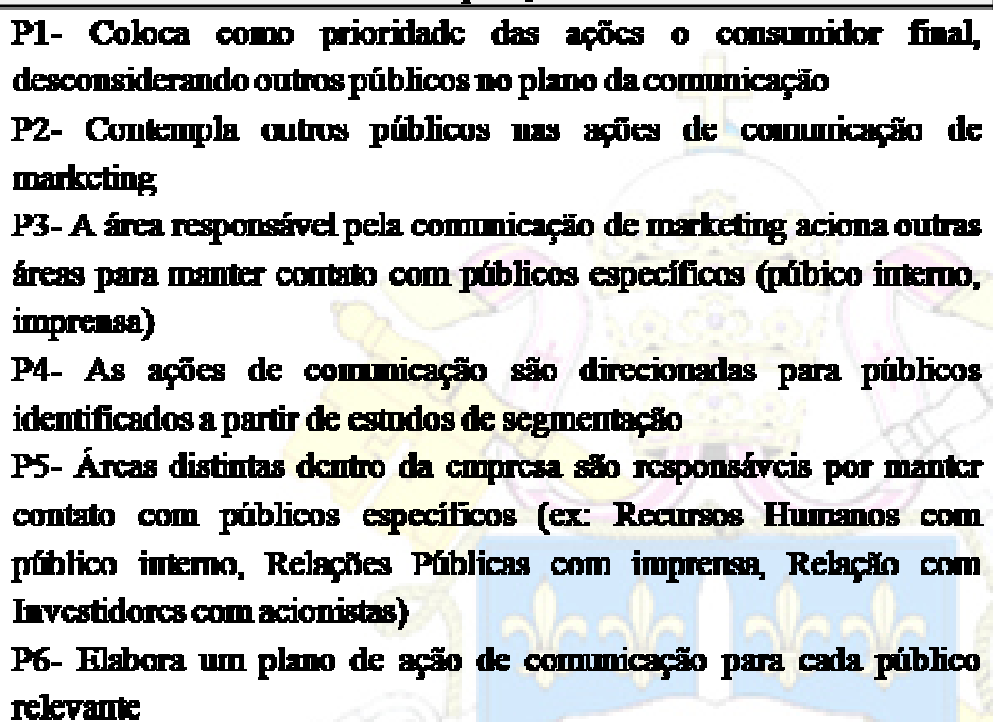 & $\begin{array}{l}\text { Dahlen, Lange e Sinith } \\
\text { (2010) } \\
\text { Fill (2002) } \\
\text { Kliatehlo (2008) } \\
\text { Ogdene Crescitelli (2007) } \\
\text { Smifi, Berry e Pulford } \\
\text { (1997) }\end{array}$ \\
\hline
\end{tabular}

Fonte: Elaborado pelos autores

Uma vez definidas as proposições, a etapa seguinte foi a classificação dos elementos de acordo com as proposições, de modo a organizar os trechos das entrevistas. Posteriormente as proposições foram codificadas e foi feita a verificação da frequência com que cada uma surgiu nas entrevistas. Por fim, partiu-se para a elaboração das tabelas de resultados que sintetizam e destacam as informações fornecidas pela análise.

\section{Análise dos resultados}

A análise dos resultados destaca como as empresas têm abordado a questão das múltiplas audiências no planejamento de suas campanhas promocionais, identifica quais públicos são considerados pelas empresas no processo da comunicação, revela os grupos prioritários nas estratégias de comunicação e aqueles que exercem maior influência na condução das atividades de marketing, e evidencia as estratégias de contato implementadas pelas empresas para atingir os públicos selecionados. 
A tabela I apresenta as contagens relativas a cada proposição (Pı a P6 detalhadas no quadro 2) que representa a categoria em análise.

Tabela I - Público-alvo da comunicação de marketing

\begin{tabular}{c|c|c|c|c|c|c}
\hline Cmpresa & P1 & P2 & P3 & P4 & P5 & P6 \\
\hline 1 & 0 & 4 & 0 & 1 & 1 & 0 \\
\hline 2 & 0 & 1 & 1 & 0 & 1 & 0 \\
\hline 3 & 0 & 3 & 0 & 2 & 2 & 0 \\
\hline 4 & 0 & 2 & 2 & 1 & 2 & 3 \\
\hline 5 & 0 & 2 & 2 & 1 & 2 & 0 \\
\hline 6 & 0 & 1 & 0 & 1 & 1 & 0 \\
\hline 7 & 0 & 4 & 1 & 1 & 2 & 0 \\
\hline 8 & 0 & 3 & 0 & 1 & 1 & 0 \\
\hline 9 & 1 & 0 & 0 & 0 & 0 & 0 \\
\hline 10 & 0 & 2 & 2 & 1 & 1 & 2 \\
\hline Total & 1 & 22 & 8 & 9 & 13 & 5 \\
\hline
\end{tabular}

Fonte: Elaborado pelos autores

Os resultados apontam que existe por parte da maioria das empresas a preocupação em se estender a comunicação de marketing para outros públicos de interesse, considerando que essa proposição foi a mais mencionada ( $\mathrm{P}_{2}, 22$ citações). A valorização desta ampliação foi mais evidenciada nas empresas i e 7 e as colocações dos respectivos entrevistados traduzem a realidade das outras empresas também e revelam que a comunicação no atual contexto deve contemplar todos aqueles públicos que a organização entende como prioritário para que suas ações consigam ser bem-sucedidas. De acordo com um entrevistado, "Eu necessariamente tenho que olhar todos esses targets, e eles devem estar previstos na minha comunicação”.

Levando em conta que os entrevistados declararam que a comunicação de marketing é direcionada para outros públicos de interesse, optou-se por detalhar quais são esses públicos e destacar a quantidade de citações feitas sobre cada um deles em cada entrevista (tabela 2). Esta opção revelou-se interessante para compreender quais são os alvos prioritários para as empresas no processo de comunicação de marketing. 
Tabela 2 - Detalhamento dos públicos considerados no processo de comunicação

\begin{tabular}{|c|c|c|c|c|c|c|c|}
\hline Empresa & $\begin{array}{l}\text { Influcnciadores } \\
\text { (Blogs, fónuns } \\
\text { de discussão, } \\
\text { clubes de } \\
\text { afinidadt) }\end{array}$ & Imprensa & $\begin{array}{l}\text { Intermediários } \\
\text { (varejistas, } \\
\text { atacadistas, } \\
\text { distriluriukma) }\end{array}$ & $\begin{array}{c}\text { Interno } \\
\text { (funcionários, } \\
\text { time de } \\
\text { vemdas) }\end{array}$ & Govemo & Ong's & Associaçōes \\
\hline 1 & 2 & 1 & $\mathbf{1}$ & 3 & 1 & 2 & 2 \\
\hline 2 & 1 & 1 & $\mathbf{0}$ & 1 & 1 & 1 & 1 \\
\hline 3 & 3 & 4 & 3 & 2 & 0 & $\mathbf{0}$ & 0 \\
\hline 4 & 3 & 1 & $\mathbf{0}$ & 2 & 0 & 1 & 0 \\
\hline 5 & $\mathbf{0}$ & 1 & 0 & 1 & 0 & $\mathbf{0}$ & 0 \\
\hline 6 & $\mathbf{0}$ & $\mathbf{0}$ & $\mathbf{0}$ & 0 & $\mathbf{0}$ & $\mathbf{0}$ & $\mathbf{0}$ \\
\hline 7 & $\mathbf{0}$ & 2 & 3 & $\mathbf{I}$ & $\mathbf{0}$ & $\mathbf{0}$ & $\mathbf{0}$ \\
\hline 8 & 1 & 1 & $\mathbf{0}$ & 2 & 1 & 1 & 1 \\
\hline 9 & $\mathbf{0}$ & 1 & $z^{2}$ & 0 & 0 & $\mathbf{0}$ & 0 \\
\hline 10 & 1 & 1 & 2 & 2 & 3 & 3 & 0 \\
\hline Total & 11 & 13 & 9 & 14 & 6 & 8 & 4 \\
\hline
\end{tabular}

Fonte: Elaborado pelos autores

De acordo a tabela 3 os três públicos de interesse mais citados pelos entrevistados foram: interno (I4 citações), imprensa (I3 citações) e influenciadores (II citações). No que se refere ao público interno, os resultados sugerem que as empresas têm se preocupado com este grupo no sentido de fazer com que seus integrantes conheçam antecipadamente as campanhas de comunicação que serão veiculadas no mercado, sejam informados sobre o lançamento de produtos, tenham consciência a respeito dos valores e conceitos da marca, bem como sejam alvos de campanhas de marketing exclusivas para eles. O entrevistado da empresa 8 ressaltou a sua preocupação em fazer com que a organização como um todo e, de modo especial, as equipes de marketing responsáveis pelo desenvolvimento das ações de comunicação dos serviços da empresa, compreenda o elenco de valores, princípios e aspirações que estão por trás da marca e que devem ser mantidos nas mensagens enviadas aos diferentes públicos de interesse.

$\mathrm{Na}$ fala dos entrevistados percebeu-se a força que a imprensa e os influenciadores possuem para a implementação do processo de comunicação, sendo que em alguns casos, existe a elaboração formal de planos de ação para alcançar esses grupos e, principalmente, esforços organizados para que exista uma interação concreta entre esses grupos e os produtos e serviços promovidos pelas empresas, seja por meio do envio de 
amostras para testes, fato citado pelo entrevistado da empresa 3 ou realização de eventos quando do lançamento de alguns produtos, como exemplificado pela entrevistada da empresa 4. Essas estratégias de comunicação e de relacionamento se destinam tanto para imprensa de massa, como para veículos segmentados, o mesmo ocorrendo para os blogs e fóruns de discussão, os quais foram várias vezes citados por praticamente todas as empresas. Vale ressaltar que tanto a imprensa como os influenciadores podem ser vistos como uma força adicional no desenvolvimento de uma abordagem de comunicação ao mercado, pois são capazes de disseminar rapidamente e com mais credibilidade as informações dos produtos e iniciativas da empresa. Ademais, o uso desse tipo de público torna-se importante em tempos onde a comunicação paga, especialmente a propaganda, tem passado por um processo de crise de credibilidade e descrédito.

Os intermediários, grupo formado pelos varejistas, atacadistas e distribuidores, foram mencionados exclusivamente pelas empresas industriais (9 citações), o que de certa forma era de se esperar, devido à importância deste grupo para as fabricantes, seja pelo contato direto entre eles e o consumidor final, como também por servirem de canal de distribuição dos produtos produzidos. O entrevistado da empresa 7 destacou a força do varejo no Brasil, o que, segundo seu relato, demanda uma série de ações para preservar um bom relacionamento (como o envio de convites para participar de eventos de lançamento de produtos no exterior, por exemplo) e para garantir que a comunicação com este público seja clara, para que as vantagens e características dos produtos revendidos sejam compreendidas corretamente por eles e repassadas ao consumidor. Por meio dos relatos dos entrevistados dessas indústrias, a área de comunicação de marketing parece estar bem alinhada e integrada com as atividades desenvolvidas pelas áreas dedicadas à gestão dos intermediários, como os times de vendas, trade marketing e gerentes de canal. Nesse caso, o alinhamento ocorre pelo papel desempenhado na geração de demanda para os intermediários a partir das campanhas de comunicação voltadas ao público consumidor e no suporte em ações promocionais, ações que privilegiam o aprimoramento do relacionamento e a geração de benefícios mútuos.

Os demais públicos de interesse (Governo, ONGs associações) foram mais citados pelas empresas i e Io e neste caso, as relações entre as empresas e estes grupos envolvem uma série de iniciativas, como a criação e execução de campanhas sociais e 
educacionais para crianças carentes e famílias de baixa renda, projetos de sustentabilidade, relacionamento com clubes de afinidade, etc.

Como as empresas entrevistadas são todas de grande porte, é natural que existam áreas que são responsáveis por manter contato com públicos específicos $\left(\mathrm{P}_{5}\right)$ e essa situação correspondeu a I3 citações. A proposição 3 surgiu a partir de casos onde os gestores de comunicação tentam justamente atingir públicos relevantes por meio das áreas de contato (como por exemplo, os departamentos de Relações Públicas, comunicação interna e assessoria de imprensa), acionando essas áreas em determinados momentos. Porém, levando em conta a importância dos públicos para a comunicação de marketing e o fato de existir canais indiretos de comunicação com tais públicos, o número de citações da proposição poderia ter sido maior, mas obteve apenas 8 menções.

Boa parte dos entrevistados citou que as ações de comunicação da empresa são direcionadas para públicos identificados a partir de estudos de segmentação $\left(\mathrm{P}_{4}, 9\right.$ citações). Nas empresas 3, 4, 6 e 8 observou-se que os públicos são definidos a partir do cruzamento de vários critérios e filtros, o que possibilita uma determinação específica dos alvos da comunicação e um direcionamento objetivo das ações.

Pode-se dizer que essas mesmas características foram encontradas nas empresas 7 e IO, porém, com uma particularidade: ambas fabricam e comercializam produtos globais, cujas marcas e categorias de produtos são posicionadas para os públicos determinados a partir de estudos de segmentação realizados pelas matrizes das empresas nos países de origem e que orientam a realização das campanhas nos demais locais onde as marcas estão presentes. Uma situação específica relacionada a este fator surgiu na empresa 7. Segundo o entrevistado, existe a "localização" da segmentação, que consiste na aplicação dos critérios definidos pela matriz para a realidade brasileira, com o objetivo de se orientar localmente as campanhas das categorias dos produtos.

Essa objetividade na definição de segmentos e públicos não foi encontrada nas empresas 2 e 9, considerando que as duas organizações destinam suas ofertas para um mercado abrangente e não possuem categorias de produtos ou unidades de negócios distintos que são direcionados a públicos específicos. Em decorrência disso, não houve por parte das entrevistadas menções a respeito da realização de grandes esforços na aplicação de critérios de segmentação. A empresa 9 se destacou também por outro 
motivo: é a única que não contempla outros públicos na comunicação, tendo seu foco voltado apenas para o consumidor final. Vale lembrar que esta empresa é uma organização varejista e a entrevistada afirmou que suas ações têm basicamente dois objetivos: atrair o público consumidor para as lojas da rede e contribuir para o aumento do faturamento.

Embora a maioria dos entrevistados reconheça a importância dos públicos de interesse no processo de comunicação, a proposição relacionada ao desenvolvimento de planos de ação específicos para esses públicos (P6, 5 citações) apareceu explicitamente em duas empresas (4 e Io). O principal fato relacionado a isso na empresa 4 diz respeito às menções feitas pela entrevistada sobre a importância de se definir claramente as estratégias de comunicação (em termos de objetivos pretendidos e adequação de canais de acesso) para cada segmento de clientes identificado pela instituição (pessoas físicas e jurídicas), bem como para alguns influenciadores. Já na empresa Io, esse fato está alinhado à realização de projetos em parceria com o Governo e organizações não governamentais para a disseminação de mensagens que valorizem a mudança de hábitos de saúde e higiene.

No entanto, vale ressaltar que, mesmo que as empresas não tenham processos sistematizados e planos específicos de comunicação para outros públicos, ou seja, independentemente do fato de as empresas não terem programado a recepção de algumas mensagens por determinados públicos, as mensagens de comunicação enviada por elas são transmitidas de forma praticamente natural para diversas audiências. Isso ocorre basicamente em virtude de dois fatores. O primeiro relaciona-se com a rapidez com que as mensagens circulam no atual contexto, especialmente pelas diversas plataformas de comunicação baseadas na Internet. O segundo fator repousa sobre a inexistência de fronteiras claras entre os diversos públicos de relacionamento de uma organização. Um exemplo disso foi dado pelo entrevistado da empresa I: “[...] qualquer comunicação que eu faço interna hoje acaba nas redes sociais e vira para o grande público, e qualquer comunicação que eu faço fora circula nas redes informais da organização". 


\section{Considerações Finais}

O presente artigo teve por objetivo compreender como as empresas têm abordado a questão das múltiplas audiências no planejamento de suas campanhas promocionais. De forma específica, o estudo buscou identificar quais públicos são considerados pelas empresas, os grupos prioritários nas estratégias de comunicação e aqueles que exercem maior influência na condução das atividades de marketing, além de evidenciar as estratégias de contato implementadas pelas empresas para atingir os públicos selecionados.

O referencial teórico destacou que a comunicação de marketing deve ser destinada a diferentes públicos de relacionamento da organização e não se limitar aos clientes atuais e potenciais, pois, cada um possui necessidades distintas de informação e importância relativa para a organização. Além disso, essa recomendação atende a um dos requisitos da comunicação integrada de marketing, a qual postula a necessidade de a comunicação atingir a audiências diversas para que seu efeito seja potencializado. Naturalmente o envolvimento do maior ou menor número de públicos atingidos, bem como a prioridade que cada um deles tem para a organização, são fatores que dependem de outros elementos de decisão, em especial, dos objetivos que a comunicação pretende atingir e dos recursos financeiros disponíveis.

Os resultados apontaram que as empresas buscam contemplar outros públicos no processo de comunicação de marketing, em especial, os grupos que têm recebido mais atenção correspondem ao público interno, imprensa e influenciadores. De forma geral, as empresas envolvem o público interno em comunicações que visam atingir variados objetivos, dentre eles pode-se destacar: conscientizar sobre o posicionamento e valores da marca, divulgar as ações de comunicação e campanhas de comunicação que serão dirigidas ao mercado, informar os lançamento de produtos, etc. Para a imprensa e influenciadores as empresas buscam apresentar os diferenciais e vantagens dos produtos e manter um relacionamento próximo, considerando a capacidade que eles têm de disseminar as informações para o grande público e a credibilidade junto ao mercado.

Em praticamente todos os casos os gestores de comunicação de marketing precisam acionar as áreas de contato com esses públicos para colocar em pratica suas estratégias. Muito embora isso fosse esperado, pois, todas as empresas são de grande 
porte, o fato de existir departamentos distintos que lidam com públicos relevantes para a comunicação de marketing pode tornar mais difícil o acesso a estes públicos e o envio de mensagens pode ser prejudicado, considerando que essas áreas atendem a empresa como um todo. Isso pode ocorrer mesmo em empresas que colocam à disposição da área de marketing canais internos de comunicação ou equipes de jornalistas para o contato com a imprensa.

A pesquisa apontou também que os estudos de segmentação têm auxiliado as empresas a direcionar melhor os esforços de comunicação, especialmente nos casos onde a organização oferta ao mercado bens e serviços direcionados a diferentes segmentos de mercado. Em apenas dois casos foi possível constatar a elaboração de planos de comunicação específicos para determinados públicos, sugerindo que o processo de incorporar diferentes audiências ainda não seja uma prática sistematizada.

As limitações do estudo fazem com que os resultados não possam ser generalizados. Dessa forma, é necessário mencionar que os achados da pesquisa são restritos às empresas que participaram do estudo. Deve-se fazer menção ao fato de que os dados coletados e analisados foram extraídos de apenas um profissional de cada empresa. Acredita-se que se as entrevistas envolvessem múltiplos respondentes as informações poderiam ser mais ricas e baseadas em outras experiências.

Futuros estudos com abordagem quantitativa e elaborados com base nos resultados da presente pesquisa poderiam ser realizados com uma amostra maior de empresas para ampliar as discussões. Recomenda-se também que novas pesquisas sejam realizadas em setores específicos, na tentativa de identificar os públicos considerados e prioritários em diferentes segmentos de mercado. A presente pesquisa foi realizada com grandes anunciantes com relativo grau de profissionalização na área de comunicação de marketing, e entende-se que estudos com empresas de médio porte poderiam trazer subsídios para a área de conhecimento e comparações interessantes.

\section{Referências}

ANDERSON, Carol H.; VINCZE, Julian W. Strategic marketing management. Boston: Houghton Mifflin Company, 2004.

BARDIN, Laurence. Análise de conteúdo. São Paulo: Edições 7o, $20 I I$. 
CRESCITELLI, Edson; IKEDA, Ana A. Planejamento de comunicação de marketing: um estudo exploratório. Revista UNICSUL, v. II, p.I49-I62, 2006.

DAHLÈN, Micael; LANGE, Fredrik; SMITH, Terry. Marketing communications: a brand narrative approach. Chichester: John Wiley \& Sons, 2OIO.

DAYMON, Christine; HOLLOWAY, Immy. Qualitative research methods in public relations and marketing communications. London: Routledge, 2 OII.

DELLAGNELO, Eloise H.L.; SILVA, Rosimeri C. Análise de conteúdo e sua aplicação em pesquisa na administração. In: VIEIRA, Marcelo M. F.; ZOUAIN, Deborah M. Pesquisa qualitativa em administração: teoria e prática. Rio de Janeiro: Editora FGV, 2005.

DUARTE, Jorge. Entrevista em profundidade. In: DUARTE, Jorge; BARROS, Antonio (org.). Métodos e técnicas de pesquisa em comunicação. São Paulo: Atlas, 2005.

FILL, Chris. Marketing communications: contexts, strategies, and applications. Harlow: Prentice Hall, 2002.

IKEDA, Ana A.; CRESCITELLI, Edson. O efeito potencial da comunicação integrada de marketing.

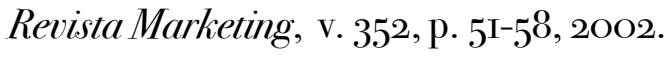

KLIATCHKO, Jerry G. Revisiting the IMC construct: a revised definition and four pillars. International Journal of Advertising, v. 27, n. I, p. I33-I60, 2008.

KOTLER, Philip; KELLER, Kevin L. Administração de marketing. São Paulo: Prentice-Hall, 2006.

MOORE, Jeri; THORSON, Esther. Strategic planning for integrated marketing communications programs. In: THORSON, Esther; MOORE, Jeri (ed). Integrated communication: synergy of persuasive voices. Mahwah: Lawrence Erlbaum Associates, I996.

MOZZATO, Anelise R. Análise de conteúdo como técnica de análise de dados qualitativos no campo da administração: potencial e desafios. In: Encontro Anual da Associação Nacional de Programas de Pós-Graduação em Administração. ENANPAD, 20Io, Rio de Janeiro, Anais...Rio de Janeiro: ANPAD, 2OIO.

NICKELS, William G.; WOOD, Marian B. Marketing: relacionamentos, qualidade e valor. Rio de Janeiro: LTC, I999.

OGDEN, James R.; CRESCITELLI, Edson. Comunicação integrada de marketing: conceitos, técnicas e práticas. São Paulo: Pearson Prentice Hall, 2007.

OLIVEIRA, Eliana; ENS, Romilda T.; ANDRADE, Daniela B.S.F.; DE MUSIS, Carlo R. Análise de conteúdo e pesquisa na área da educação. Revista Diálogo Educacional, v. 4, n. 9, p. II-28, 2003.

ROSSITER, John R.; PERCY, Larry. Advertising communications and promotion management. New York: McGraw-Hill, I997.

SCHULTZ, Don E.; TANNENBAUM, Stanley I.; LAUTERBORN, Robert F. O novo paradigma do marketing: como obter resultados mensuráveis através do uso de database e das comunicações integradas de marketing. São Paulo: Makron Books, 1994.

SHIMP, Terence A. Comunicação integrada de marketing: propaganda e promoção. Porto Alegre: Bookman, 2009. 
SMITH, Paul; BERRY, Chris; PULFORD, Alan. Strategic marketing communications: new ways to build and integrate communication. London: Kogan Page Limited, I997.

THORSON, Esther; MOORE, Jeri. Introduction. In: THORSON, Esther; MOORE, Jeri (ed). Integrated communication: synergy of persuasive voices. Mahwah: Lawrence Erlbaum Associates, I996. 